\title{
Factors Affecting Public Adoption of COVID-19 Prevention and Treatment Information During an Infodemic: Cross-sectional Survey Study
}

Yangyang Han", BS; Binshan Jiang ${ }^{*}$, BS; Rui Guo, PhD

School of Public Health, Capital Medical University, Beijing, China

*these authors contributed equally

Corresponding Author:

Rui Guo, PhD

School of Public Health

Capital Medical University

No.10 Youanmenwai, Xitoutiao

Beijing

China

Phone: 8601083911573

Email: guorui@ccmu.edu.cn

\begin{abstract}
Background: With the spread of COVID-19, an infodemic is also emerging. In public health emergencies, the use of information to enable disease prevention and treatment is incredibly important. Although both the information adoption model (IAM) and health belief model (HBM) have their own merits, they only focus on information or public influence factors, respectively, to explain the public's intention to adopt online prevention and treatment information.

Objective: The aim of this study was to fill this gap by using a combination of the IAM and the HBM as the framework for exploring the influencing factors and paths in public health events that affect the public's adoption of online health information and health behaviors, focusing on both objective and subjective factors.

Methods: We carried out an online survey to collect responses from participants in China (N=501). Structural equation modeling was used to evaluate items, and confirmatory factor analysis was used to calculate construct reliability and validity. The goodness of fit of the model and mediation effects were analyzed.

Results: The overall fitness indices for the model developed in this study indicated an acceptable fit. Adoption intention was predicted by information characteristics $(\beta=.266, P<.001)$ and perceived usefulness $(\beta=.565, P<.001)$, which jointly explained nearly $67 \%$ of the adoption intention variance. Information characteristics $(\beta=.244, P<.001)$, perceived drawbacks $(\beta=-.097$, $P=.002)$, perceived benefits $(\beta=.512, P<.001)$, and self-efficacy $(\beta=.141, P<.001)$ jointly determined perceived usefulness and explained about $81 \%$ of the variance of perceived usefulness. However, social influence did not have a statistically significant impact on perceived usefulness, and self-efficacy did not significantly influence adoption intention directly.

Conclusions: By integrating IAM and HBM, this study provided the insight and understanding that perceived usefulness and adoption intention of online health information could be influenced by information characteristics, people's perceptions of information drawbacks and benefits, and self-efficacy. Moreover, people also exhibited proactive behavior rather than reactive behavior to adopt information. Thus, we should consider these factors when helping the informed public obtain useful information via two approaches: one is to improve the quality of government-based and other official information, and the other is to improve the public's capacity to obtain information, in order to promote truth and fight rumors. This will, in turn, contribute to saving lives as the pandemic continues to unfold and run its course.
\end{abstract}

(J Med Internet Res 2021;23(3):e23097) doi: 10.2196/23097

\section{KEYWORDS}

information adoption; infodemic; China; health information; infodemiology; COVID-19; public health 


\section{Introduction}

\section{Background}

The global outbreak and rapid spread of the COVID-19 pandemic has led the world's public health and safety systems to face great challenges. As of April 16, 2020, the COVID-19 pandemic has affected at least 211 countries, with 2,362,704 confirmed cases and more than 165,006 deaths globally, while China has confirmed 82,367 cases and the cumulative number of deaths was 3342 [1]. The disease rapidly spread in China because of the massive population migration (ie, Chunyun, also known as the Spring Festival travel rush, which refers to a human migration during this festival) and lack of prevention and control information during the early stage of the pandemic. Moreover, the World Health Organization (WHO) has not only signaled the health risks of COVID-19 but has also labeled the situation as an infodemic, due to the amount of information, both truth and rumors, circulating around this topic [2,3].

Although public health information dissemination represents an exciting combination of broadcasting, sharing, and retrieving relevant health information [4,5], the COVID-19 infodemic did not come as a surprise [6]. The massive growth of health information on the internet was seen to be a real problem [4]. Too much information makes it difficult to find trustworthy sources of information and may harm people's health. Therefore, the quality of online health information is essential, especially when truth and rumors were still intertwined, which caused the infodemic. However, in the process of fighting COVID-19, the WHO and health authorities worldwide have been working closely with social media platforms, including Facebook, Google, Twitter, and YouTube, to provide evidence-based information to the general public in order to actively counter the rumors that have been circulating [7]. Prevention and treatment information about COVID-19 continues to spread and has an influence on populations.

At the same time, the lack of transparent, timely, and effective risk communication by health authorities regarding this emerging infectious disease in its early stage failed to bring about the appropriate level of public awareness and behavioral responses, such as avoidance of mass gatherings and personal protection in China, Europe, and the United States [8]. Online guidelines providing information for prevention and treatment are inconsistent in adapting to new knowledge, and changing or conflicting information can also confuse the public [9].

Since the beginning of the COVID-19 pandemic, information consumption has increased rapidly and significantly [10]. The new generation of health care consumers consists of an informedpublic, gleaning truth and rumors about health information with both positive and negative effects on themselves [11]. During periods of SARS spread, most people obtained SARS information from television [12]. By the time the Zika virus emerged in 2015-2016, Google Trends showed a significant increase in public searches on the internet related to the Zika virus [13], and the number of searches on video platforms, such as YouTube, had also increased rapidly [14]. Internet-based platforms that people utilized became diversified. During the COVID-19 pandemic, social distancing and stay-at-home restrictions caused the public to be fully exposed to social media; during this time, people actively searched or passively received a large amount of health-related information to prevent and treat diseases. In China, social media platforms, such as WeChat and Douyin (ie, TikTok), played an essential role in obtaining information after the virus began spreading [15]. However, studies have confirmed that over one-quarter of the most viewed YouTube videos about COVID-19 contained rumors, and these reached millions of viewers worldwide [16]. Therefore, determining whether people can use the prevention and treatment information they find on social media is critical in this pandemic.

Moreover, identifying health information from prevention and control measures is a major blind spot for the public. The public are partly responsible for selecting and filtering trustworthy health information [17]. Research shows that more than half of respondents trust almost all information online [18], and people are more likely to believe health rumors because of basic safety needs [19]. As the core part of health behavior theory, behavior intention is the subjective possibility of engaging in certain behavior. Some studies have confirmed that variables in the health belief model (HBM) can materially affect information adoption intention, and this process will affect subsequent health behaviors [20].

Therefore, if concern about identifying trustworthy information is reflected in the global population, we believe that the influencing factors in the subjective and objective aspects of engaging in that behavior may affect information adoption. Motivated by previous studies, this study was based on the information adoption model (IAM) and the HBM. The aim of this study was to explore the influencing factors and paths during public health events that affect the public's intention to adopt online prevention and treatment information under the infodemic. We aim to provide a basis for decision making and policy suggestions in order to deal with online health information governance in the internet era. Moreover, this study adds to the sparse literature on information adoption.

\section{Research Model and Hypotheses}

\section{Information Adoption Model}

Sussman and Siegal first proposed the IAM based on the technology acceptance model (TAM) and the theoretical perspective of the elaboration likelihood model (ELM), which regards how information influences people's decision making as the process of information adoption [21]. From the TAM, a critical aspect of how individuals act on an advocated issue or behavior is the extent to which they believe the information contained within a message is useful [21,22]. From the ELM, this process depends on elaboration likelihood, and two likely antecedents of usefulness have been suggested from this stream of research as well as two key internal validity factors [21]. The ELM explains how individuals adopt information and then change their will and behavior. Moreover, recent literature has also demonstrated that this model can be applied in the context of online information acceptance, argument quality, and source credibility; these are taken as the direct objects of information adoption, and their influence has been repeatedly verified $[23,24]$. Simultaneously, individuals' perceived information 
usefulness based on information quality and source characteristics plays a crucial intermediary role in information adoption. Health information as a type of information fits into the IAM's influencing factors. The essence of information adoption is when individuals are persuaded by the received information and then accept the opinions or propositions expressed in the information.

\section{Health Belief Model}

The HBM has been widely used to explain preventive health behavior [25] and is one of the first and the best-known social cognition models. It focuses on the relationship of health behaviors, practices, and utilization of health services. From its initial design to predict behavioral response to the treatment received by chronic patients [26], it has been validated in different studies. Contemporary research studies have recently focused on the general health behavior of the population $[27,28]$. The core concept of HBM is people's perception of disease threat and an assessment of their behavior. The assessment of behavior includes evaluating the effectiveness of behavior, the input and outcome of behavior change, and the obstacle to its implementation [28].

Furthermore, researchers added cues to action, meaning the stimuli or cues that catalyze action. Cues are divided into external cues, such as mass media, and internal cues, such as physical discomfort, that limit people's beliefs about behavioral health consequences and behavioral effects. The HBM has been widely used in health behavior change [20], which provides scientific theoretical support for understanding the impact of health information propagation on the audience's health behavior. It has become one of the most comprehensive models to understand health-related behaviors and why people undertake, or do not undertake, actions to prevent or control illnesses [29].

\section{Integrated Model of IAM and HBM}

Although IAM and HBM are commonly used models, the use of these models independently has not fully explained online health information adoption behavior. IAM focuses on the influence of information characteristics on information adoption without considering the individual's subjective status quo. However, the information's influence might change from person to person; the same content can evoke differing notions among receivers [30]. Also, HBM only considers the public's cognitive information to predict general health behavior without influencing the process. More specifically, this study argues that an individual's motivation to adopt health information will depend on the individual's subjective and information-related objective factors. It is also supported by Erkan and Evans' information acceptance model (IACM), in which a conceptual model was developed based on the integration of IAM and the theory of reasoned action; this model confirmed the influences of both information adoption and attitude toward information on consumers' purchase intentions and the influence of information usefulness on information adoption [31]. In IACM, information quality, information credibility, and information needs were all found to affect information usefulness [31]. In addition, Ahadzadeh et al combined the TAM and HBM to study health-related internet use [32]. This study demonstrated that individuals who perceived their health to be at risk, or were motivated to use the internet when they believed that the internet was useful for providing health and health management information, would be expected to have a positive attitude toward internet use for health purposes [32].

Our research mainly focused on information adoption behavior during the COVID-19 infodemic; therefore, we developed the IAM-HBM model by considering information characteristics (ie, objective factors) and the public's health beliefs (ie, subjective factors) about information. Also, the HBM has been criticized for not considering environmental factors, such as social influence (ie, friends, family, and individuals' internet providers), that can influence health-related behavior [33]. Therefore, we proposed the following path: social influence impacts perceived usefulness of information. Figure 1 shows the conceptual model proposed by this study, which incorporates information characteristics, social influence, perceived drawbacks, perceived benefits, self-efficacy, perceived usefulness, and adoption intention. 
Figure 1. Integrated model based on the information adoption model and health belief model. H: hypothesis.

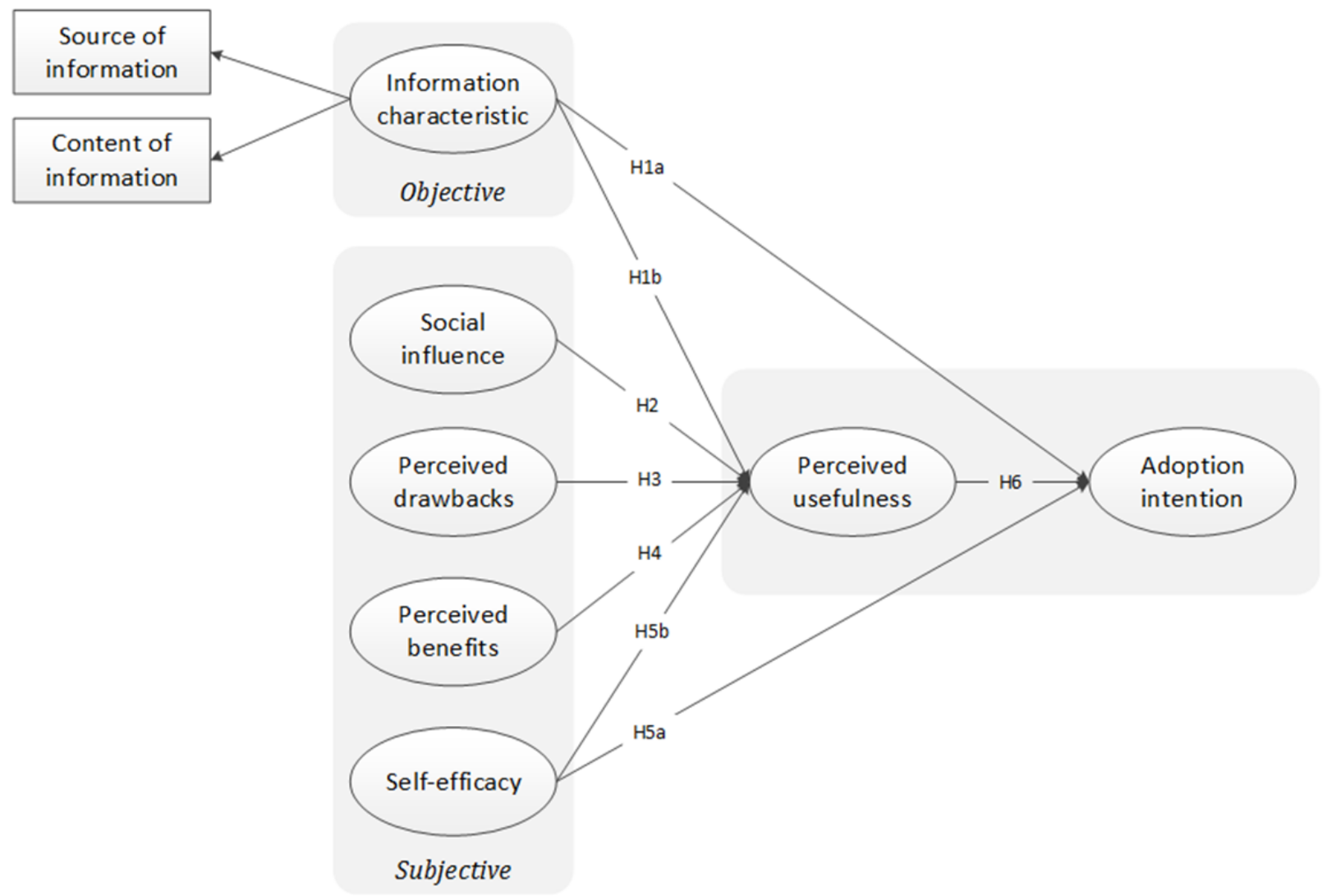

\section{Hypotheses}

Information characteristics refer to whether the prevention and treatment information about COVID-19 to which individuals are exposed from the internet is persuasive and to how individuals perceive the credibility of the information source, including the content and source attributes of the information. Sussman and Siegal believed that information characteristics, including quality and source, impacted people's perceived information usefulness, which then affected information adoption; they also believed that information characteristics impacted individuals' information adoption directly, which was measured by information adoption intention [21]. Thus, information characteristics are applied to our IAM-HBM model as verified factors in the IAM, impacting individuals' perceived usefulness of COVID-19 prevention and treatment information. Based on this, we hypothesized the following:

1. Hypothesis 1a. Information characteristics are positively associated with the intention to adopt COVID-19 prevention and treatment information.

2. Hypothesis $1 \mathrm{~b}$. Information characteristics are positively associated with perceived usefulness of COVID-19 prevention and treatment information.

Social influence refers to how individuals perceive the influence of those around them when they adopt COVID-19 prevention and control information. Venkatesh et al defined social influence as the degree to which users were affected by people around them using new technologies and systems; this included integrated subjective norms, social factors, and images [34]. The construct of social influence was added to the extended
HBM to enhance the prediction ability of the model. Perceived usefulness was mediated by external variables, including social influence [35,36].

Perceived drawbacks refer to the difficulties that individuals may encounter when adopting the prevention and treatment information of COVID-19 on the internet. Such difficulties become apparent by the predicted cost of adopting healthy behaviors, including tangible and intangible costs. Tangible cost refers to the cost of perceived usefulness of information, usually measured in monetary terms. Intangible cost refers to the effort required to confirm the usefulness of information, such as time and energy [37,38]. Based on HBM, perceived drawbacks were confirmed as the most powerful single predictor of intended expectations [39]. Yun built an integrated model and verified that perceived drawbacks affect people's actions in seeking health information through perceived usefulness [40]. If social media users do not need to spend too much money or physical and mental energy, they can reduce the cost of using technology, and their total perceived usefulness will increase when searching for online health information [41].

Perceived benefits refer to the benefits that individuals may give themselves if they adopt the prevention and treatment information about COVID-19 on the internet. In the research on the HBM, Rosenstock proposed that individuals would weigh the effectiveness of behaviors through cost-benefit analysis when they adopt healthy behaviors. The perception of benefits provided a more preferential action path $[41,42]$. The positive experiences gained by individuals from acquiring and adopting health information behavior will promote the overall value 
perception of this behavior. This will further strengthen the intention of continuing to search for health information [41]. Building on findings by Rosenstock, we explored whether perceived benefits are associated with perceived usefulness. Thus, perceived benefits were applied to this IAM-HBM model as a factor that estimates individuals' beliefs about the usefulness of COVID-19 prevention and treatment information.

Self-efficacy refers to the level of confidence in an individual's ability to prevent and treat COVID-19. As an essential part of social cognitive theory, self-efficacy refers to people's confidence in performing a specific behavior. The higher the expectations, the higher the tendency to make more considerable efforts. This concept has been widely used to understand health behavior change. Self-efficacy also had an impact on health information-seeking behavior [43]. Information on the internet regarding people's health interventions significantly improved the specific behaviors of self-efficacy, including physical exercise and healthy eating. Physiological and social advantages caused people to have more positive behavior change expectations.

Yun's integrated model demonstrated that internet self-efficacy affected users' actions through perceived usefulness when seeking health information on the internet [40]. We gravitate toward the idea that self-efficacy is a determinant of adoption intention.

Based on the discussion above, we hypothesized the following:

1. Hypothesis 2. Social influence is positively associated with perceived usefulness of COVID-19 prevention and treatment information.

2. Hypothesis 3. Perceived drawbacks are negatively associated with perceived usefulness of COVID-19 prevention and treatment information.

3. Hypothesis 4. Perceived benefits are positively associated with perceived usefulness of COVID-19 prevention and treatment information.

4. Hypothesis 5a. Self-efficacy is positively associated with COVID-19 prevention and treatment information adoption.
5. Hypothesis 5b. Self-efficacy is positively associated with perceived usefulness of COVID-19 prevention and treatment information.

Perceived usefulness refers to an individual's blanket perception of COVID-19 prevention and treatment information on the internet. It is plausible that adopting such healthy behaviors can meet individuals' health needs and help them achieve healthy outcomes. Usefulness, utility, and perceived usefulness, which were first applied to TAM by Davis et al, are used to evaluate the utility of information-seeking behavior [22]. As the crucial variable of IAM, perceived usefulness has a significant influence on adoption intention. Thus, perceived usefulness is applied to this IAM-HBM model as a factor that could influence individuals' COVID-19 prevention and treatment information adoption. In our paper, Hypothesis 6 states that perceived usefulness is positively associated with the intention to adopt COVID-19 prevention and treatment information.

\section{Methods}

\section{Data Collection and Participants}

Online questionnaires were powered by the survey platform WJX (Changsha Ranxing Information Technology Co), whose web application was embedded into social media platforms from March 24 to April 5, 2020. The electronic version of the questionnaire was uploaded to the WJX web application; respondents (ie, Chinese people in China) could fill in, submit, and share the questionnaire using a Quick Response (QR) code or using a forwarding link issued by the WJX web application. The data were collected using snowball sampling through repetitive one-to-many sharing on social media, a nonprobability sampling method; there were 528 respondents from 30 provinces in China. We gathered data using an online survey because of public space restrictions and because netizens were potentially exposed to the infodemic. After eliminating invalid responses through data filtering, 501 valid questionnaires out of 528 remained (94.9\% validity rate). Table 1 shows the demographic characteristics of the sample population. 
Table 1. Demographic characteristics of participants.

\begin{tabular}{|c|c|}
\hline Characteristic & Value $(\mathrm{N}=501), \mathrm{n}(\%)$ \\
\hline \multicolumn{2}{|l|}{ Gender } \\
\hline Male & $216(43.1)$ \\
\hline Female & $285(56.9)$ \\
\hline \multicolumn{2}{|l|}{ Age (years) } \\
\hline $18-19$ & $6(1.2)$ \\
\hline $20-29$ & $154(30.7)$ \\
\hline $30-39$ & $122(24.4)$ \\
\hline $40-49$ & $81(16.2)$ \\
\hline $50-59$ & $77(15.4)$ \\
\hline $60-69$ & $51(10.2)$ \\
\hline $70-79$ & $8(1.5)$ \\
\hline$\geq 80$ & $2(0.4)$ \\
\hline \multicolumn{2}{|l|}{ Education } \\
\hline Junior high school diploma or below & $21(4.2)$ \\
\hline Senior high school diploma & $66(13.2)$ \\
\hline College graduate & $84(16.8)$ \\
\hline Bachelor's degree & $256(51.1)$ \\
\hline Master's degree or above & $74(14.8)$ \\
\hline \multicolumn{2}{|l|}{ Occupation } \\
\hline Student & $104(20.8)$ \\
\hline Officer $^{\mathrm{a}}$ & $50(10.0)$ \\
\hline Enterprise manager & $67(13.4)$ \\
\hline Office staff or clerk & $62(12.4)$ \\
\hline Professional $^{\mathrm{b}}$ & $75(15.0)$ \\
\hline Worker or laborer & $24(4.8)$ \\
\hline Business service & $14(2.8)$ \\
\hline Self-employed & $12(2.4)$ \\
\hline Freelancer & $22(4.4)$ \\
\hline Farmer & $2(0.4)$ \\
\hline Retired & $63(12.6)$ \\
\hline No profession ${ }^{\mathrm{c}}$ & $6(1.2)$ \\
\hline
\end{tabular}

${ }^{\mathrm{a}}$ Officer occupations include government officials, cadres, and civil servants.

${ }^{\mathrm{b}}$ Professional occupations include doctors, lawyers, journalists, teachers, etc.

${ }^{\mathrm{c}}$ No profession includes temporary occupation or unemployed.

Out of the 501 valid responses, $216(43.1 \%)$ were from male participants and the other $285(56.9 \%)$ were from female participants. Further, the majority of respondents were between the ages of 20 and 39 years $(276 / 501,55.1 \%)$. Most of the respondents had earned a bachelor's degree $(256 / 501,51.1 \%)$, which indicated a high level of education among respondents. In terms of occupation, the largest group was students (104/501, $20.8 \%$ ), followed by professionals $(75 / 501,15.0 \%)$ and enterprise managers $(67 / 501,13.4 \%)$.

\section{Quality Control}

We conducted quality control through the survey platform and via the investigators. Once on the platform, respondents were invited to fill in the questionnaire voluntarily. Each Internet Protocol (IP) address, computer, or username could only be used once. Also, there were various filtering rules for invalid answers, such as spending too little time on a questionnaire and trap rules to filter out random answers. 
After the surveys were submitted, the respondents were screened by the investigators to retain the valid questionnaires. We excluded the following respondents: those who failed the attention check, where the answers to all the questions were the same or cyclical; those with response times of less than 120 seconds; those under 18 years old; and non-Chinese residents. Also, we checked the consistency between the IP address and the selected region, and questionnaires were eliminated if the IP addresses were not consistent.

\section{Measures}

The study instrument was modified from those in the relevant existing literature. Measurements and scales were translated into the appropriate Chinese versions to ensure the completeness and accuracy of instruments. After the repeated pretest, the final questionnaire was translated back into English, and the main semantics were not changed, indicating a strong correlation with the original English questionnaire (see Table 2 [21,29,34,44-52]). The instruments were measured using a 5-point Likert scale, ranging from 1 (highly disagree) to 5 (highly agree). All dimensions included three items, except the information characteristics construct, which included five items. 
Table 2. Measurement items of the constructs.

\begin{tabular}{ll}
\hline Construct and variables & Measurement item \\
\hline Information characteristics (IC) $[\mathbf{2 1 , 4 5 , 4 6 ]}$ & \\
IC1 & COVID-19 prevention and treatment information on the internet is appropriate for my health demands. \\
IC2 & COVID-19 prevention and treatment information on the internet is understandable. \\
IC3 & $\begin{array}{l}\text { COVID-19 prevention and treatment information on the internet is shared by most people (eg, by } \\
\text { thumb-up or retweet). }\end{array}$ \\
IC4 & $\begin{array}{l}\text { The argument for COVID-19 prevention and treatment information on the internet is compelling. } \\
\text { IC5 }\end{array}$ \\
& $\begin{array}{l}\text { The publisher of COVID-19 prevention and treatment information on the internet is experienced in } \\
\text { the health field. }\end{array}$
\end{tabular}

Social influence (SI) $[44,47]$

SI1

SI2

SI3

Perceived drawbacks (PD) [48,49]

PD1

PD2

PD3

Perceived benefits (PB) [29]

PB1

PB2

PB3

Self-efficacy (SE) [50]

SE1

SE2

SE3

Perceived usefulness (PU) [46,51]

PU1

PU2

PU3

Adoption intention (AI) [34,52]

AI1

AI2

$\mathrm{AI} 3$
People who are important to me think I should get COVID-19 prevention and treatment information from the internet.

My family and friends have obtained COVID-19 prevention and treatment information from the internet.

It is prevalent to get COVID-19 prevention and treatment information from the internet.

It may take me too much time or expense to adopt COVID-19 prevention and treatment information from the internet.

Adopting COVID-19 prevention and treatment information from the internet may cause psychological stress.

The health risks associated with the adoption of COVID-19 prevention and treatment information from the internet may outweigh the positive health outcomes.

It is important for me to adopt COVID-19 prevention and treatment information to reduce my risk of COVID-19 infection.

Adopting COVID-19 prevention and treatment information can help me stay healthy, which is very important to me.

The adoption of COVID-19 prevention and treatment information is valuable for me in order to adopt COVID-19 prevention behaviors.

I am confident that I can avoid COVID-19.

I can figure out how to avoid COVID-19 infection.

Even if I contract COVID-19, I can recover soon.

The COVID-19 prevention and treatment information on the internet is valuable to me in preventing COVID-19.

I can make good use of COVID-19 prevention and treatment information on the internet in my life.

COVID-19 prevention and treatment information on the internet can improve the health of my family, friends, and myself.

I will recommend this COVID-19 prevention and treatment information to my family and friends.

I will use this COVID-19 prevention and treatment information obtained from the internet in my daily life.

I would like to adopt COVID-19 prevention and treatment information, even if it takes my time or money (ie, to buy drugs, protective equipment, etc) to do so. 


\section{Ethics Approval and Consent to Participate}

This study was approved in writing by the Medical Ethics Committee of Capital Medical University (No. Z2019SY014) and all participants gave informed consent.

\section{Results}

\section{Overview}

After data collection, the two-stage procedure of structural equation modeling (SEM) was applied to conduct data analysis [41]. The first procedure examined scale validity from the measurement model by confirmatory factor analysis (CFA), while the second procedure interpreted hypotheses testing by the structural model. Both SPSS Statistics for Windows, version 19.0 (IBM Corp), and SPSS Amos, version 24.0 (IBM Corp), were adopted as the tools for analyzing the data.

\section{Measurement Model}

\section{Reliability}

In this study, questionnaire items had a factor loading of 0.592 and above (see Table 3), which met the evaluation standard that the factor loading for construct measures must exceed 0.5 to be retained [53]. Cronbach $\alpha$ should be at least .70, and high reliability is assumed if it is greater than .80 [54]. The composite reliability (CR) value of greater than 0.70 represented high reliability [53]. All the constructs had both high Cronbach $\alpha$ and CR values, indicating high reliability (see Table 3 ).

\section{Convergent Validity}

Convergent validity measures the correlation of a dimension's multiple indicators. This study used the average variance extracted (AVE) to estimate the convergent validity [53]. A dimension with an AVE value over 0.50 would be considered as having high convergent validity [55]. As shown in Table 3, all dimensions had AVE values that were higher than the aforementioned cutoff values, which suggest good convergent validity.

In addition, all factor loadings for indicators measuring the same construct were statistically significant (see Table 3), suggesting that all indicators effectively measured their corresponding construct [56] and supported convergent validity. 
Table 3. Reliability and convergent validity.

\begin{tabular}{|c|c|c|c|c|}
\hline Construct and scale items & Factor loading $^{\mathrm{a}}$ & Cronbach $\alpha^{\mathrm{b}}$ & Composite reliability coefficient ${ }^{\mathrm{b}}$ & Average variance extracted ${ }^{b}$ \\
\hline Information characteristics (IC) & & .903 & 0.904 & 0.654 \\
\hline IC1 & 0.822 & - & - & - \\
\hline IC2 & 0.765 & - & - & - \\
\hline IC3 & 0.858 & - & - & - \\
\hline IC4 & 0.840 & - & - & - \\
\hline IC5 & 0.754 & - & - & - \\
\hline Social influence (SI) & & .834 & 0.841 & 0.642 \\
\hline SI1 & 0.702 & - & - & - \\
\hline SI2 & 0.926 & - & - & - \\
\hline SI3 & 0.758 & - & - & - \\
\hline Perceived drawbacks (PD) & & .753 & 0.756 & 0.510 \\
\hline PD1 & 0.633 & - & - & - \\
\hline PD2 & 0.789 & - & - & - \\
\hline PD3 & 0.712 & - & - & - \\
\hline Perceived benefits (PB) & & .894 & 0.897 & 0.745 \\
\hline PB1 & 0.835 & - & - & - \\
\hline PB2 & 0.930 & - & - & - \\
\hline PB3 & 0.820 & - & - & - \\
\hline Self-efficacy (SE) & & .773 & 0.788 & 0.558 \\
\hline SE1 & 0.837 & - & - & - \\
\hline SE2 & 0.790 & - & - & - \\
\hline SE3 & 0.592 & - & - & - \\
\hline Perceived usefulness (PU) & & .884 & 0.885 & 0.719 \\
\hline PU1 & 0.826 & - & - & - \\
\hline PU2 & 0.869 & - & - & - \\
\hline PU3 & 0.849 & - & - & - \\
\hline Adoption intention (AI) & & .868 & 0.875 & 0.702 \\
\hline AI1 & 0.831 & - & - & - \\
\hline AI2 & 0.944 & - & - & - \\
\hline AI3 & 0.723 & - & - & - \\
\hline
\end{tabular}

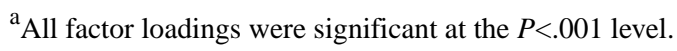

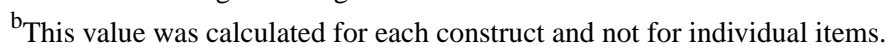

\section{Discriminant Validity}

Discriminant validity is achieved if the correlations between different constructs are relatively significant. The chi-square difference test can assess the discriminant validity of every two constructs by calculating the difference of the chi-square

statistics for the constrained and unconstrained measurement models [57]. In this study, except for perceived drawbacks, the other six dimensions' chi-square difference tests were significant at the $P=.05$ level (see Table 4). Accordingly, the results demonstrated that discriminant validity was successfully achieved for the measurement model. 
Table 4. Correlation analysis among constructs to determine discriminant validity. ${ }^{\mathrm{a}}$

\begin{tabular}{|c|c|c|c|c|c|c|c|}
\hline Construct & $\mathrm{IC}^{\mathrm{b}}$ & $\mathrm{SI}^{\mathrm{c}}$ & $\mathrm{PD}^{\mathrm{d}}$ & $\mathrm{PB}^{\mathrm{e}}$ & $S E^{f}$ & $\mathrm{PU}^{\mathrm{g}}$ & $\mathrm{AI}^{\mathrm{h}}$ \\
\hline IC & 0.809 & $-\mathrm{i}$ & - & - & - & - & - \\
\hline SI & 0.729 & 0.801 & - & - & - & - & - \\
\hline PD & -0.044 & -0.040 & 0.714 & - & - & - & - \\
\hline PB & 0.741 & 0.799 & -0.068 & 0.863 & - & - & - \\
\hline SE & 0.437 & 0.421 & 0.023 & 0.512 & 0.747 & - & - \\
\hline PU & 0.773 & 0.761 & -0.152 & 0.857 & 0.555 & 0.848 & - \\
\hline AI & 0.723 & 0.664 & -0.038 & 0.741 & 0.479 & 0.792 & 0.838 \\
\hline
\end{tabular}

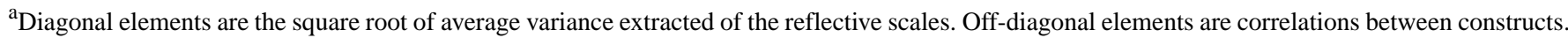

${ }^{\mathrm{b}} \mathrm{IC}$ : information characteristics.

${ }^{\mathrm{c}} \mathrm{SI}$ : social influence.

${ }^{\mathrm{d}} \mathrm{PD}$ : perceived drawbacks.

${ }^{\mathrm{e}} \mathrm{PB}$ : perceived benefits.

${ }^{\mathrm{f}} \mathrm{SE}$ : self-efficacy.

gPU: perceived usefulness.

${ }^{\mathrm{h}} \mathrm{AI}$ : adoption intention.

${ }^{\mathrm{i}}$ Repeated values were not included for easier comparison of table values.

Suppose the absolute value of the correlation coefficient is less than the square root of the AVE value. That would indicate that each construct has a certain correlation and a certain degree of differentiation between constructs, indicating that the scale data have an ideal discriminant validity. The value of the AVE square root of each construct was greater than the square of its correlation coefficient with the dimensions of all dimensions.

\section{Structural Model Analysis}

Based on the results of the CFA and modification index of indicator variables, six standard model fit criteria were used to assess the model's overall goodness of fit: ratio of the chi-square

value to the degrees of freedom $\left(\chi^{2} / \mathrm{df}\right)$, goodness-of-fit index (GFI), comparative fit index (CFI), Tucker-Lewis index (TLI), root mean square residual, and root mean square error of approximation (RMSEA).

As shown in Table 5, comparison of all fit indices with their corresponding recommended values provided evidence of a good model fit: $\chi^{2} / \mathrm{df}$ values were between 1.0 and 3.0; GFI, CFI, and TLI were all greater than 0.9; and RMSEA was smaller than 0.08. This demonstrated that the measurement model exhibited a tolerably good fit with the data collected [56].

Table 5. Goodness of fit of the measurement and structural models.

\begin{tabular}{lllll}
\hline Statistical check & Goodness-of-fit criteria & Measurement model & Structural model & Result \\
\hline$\chi^{2} / \mathrm{df}$ & $1.0-3.0$ & 2.685 & 2.677 & Good \\
Goodness-of-fit index & $>0.9$ & 0.908 & 0.908 & Good \\
Comparative fit index & $>0.9$ & 0.953 & 0.953 & Good \\
$\begin{array}{l}\text { Tucker-Lewis index } \\
\begin{array}{l}\text { Root mean square error of approx- } \\
\text { imation }\end{array}\end{array}-0.0 .9$ & 0.944 & 0.944 & Good \\
\end{tabular}

\section{Structure Model}

Based on the results of SEM, the fit indices of the structural model are shown in Table 5. Under the same criteria, the structure model fits the observed data as well. Meanwhile, the estimated results of the structural model provided the path coefficients shown in Table 6. Among the eight hypotheses, six paths were supported based on the valid data, significant at the $P=.01$ level, while the remaining two paths were rejected according to SEM (ie, Hypothesis 2 and Hypothesis 5a).

Adoption intention was predicted by information characteristics $(\beta=.266, P<.001)$ and perceived usefulness $(\beta=.565, P<.001)$, which jointly explained $66.8 \%$ of the adoption intention variance. Information characteristics $(\beta=.244, \quad P<.001)$, perceived drawbacks $(\beta=-.097, P=.002)$, perceived benefits $(\beta=.512, P<.001)$, and self-efficacy $(\beta=.141, P<.001)$ jointly determined perceived usefulness and explained $81.1 \%$ variance of perceived usefulness. In addition, perceived usefulness had the most significant influence on adoption intention. It revealed that perceived usefulness was an important indicator of adoption intention. Perceived benefits had the most significant direct influence on perceived usefulness, followed by information characteristics, while perceived drawbacks had a relatively low path coefficient, which indicated a negative effect at the same 
time. Since the rejection of Hypothesis 5a, it means that perceived usefulness had a complete mediating effect on self-efficacy to adoption intention. This result confirmed perceived usefulness as an intermediary variable. Surprisingly,
Hypothesis 2 was not supported in this study. The path coefficients supported six of all hypothesized relationships (see Table 6, Figure 2, and Multimedia Appendix 1).

Table 6. Testing results of the hypotheses.

\begin{tabular}{lllll}
\hline Hypothesis & Path & $\begin{array}{l}\text { Standardized path coeffi- } \\
\text { cient }(\beta)\end{array}$ & $P$ value & Result \\
\hline Hypothesis 1a & $\mathrm{IC}^{\mathrm{a}} \rightarrow \mathrm{PU}^{\mathrm{b}}$ & 0.244 & $<.001$ & Supported \\
Hypothesis 1b & $\mathrm{IC} \rightarrow \mathrm{AI}^{\mathrm{c}}$ & 0.266 & $<.001$ & Supported \\
Hypothesis 2 & $\mathrm{SI}^{\mathrm{d}} \rightarrow \mathrm{PU}$ & 0.115 & .07 & Rejected \\
Hypothesis 3 & $\mathrm{PD}^{\mathrm{e}} \rightarrow \mathrm{PU}$ & -0.097 & .002 & Supported \\
Hypothesis 4 & $\mathrm{PB}^{\mathrm{f}} \rightarrow \mathrm{PU}$ & 0.512 & $<.001$ & Supported \\
Hypothesis 5a & $\mathrm{SE}^{\mathrm{g}} \rightarrow \mathrm{PU}$ & 0.141 & $<.001$ & Supported \\
Hypothesis 5b & $\mathrm{SE} \rightarrow \mathrm{AI}$ & 0.050 & .25 & Rejected \\
Hypothesis 6 & $\mathrm{PU} \rightarrow \mathrm{AI}$ & 0.565 & $<.001$ & Supported \\
\hline
\end{tabular}

${ }^{\mathrm{a}} \mathrm{IC}$ : information characteristics.

${ }^{\mathrm{b}} \mathrm{PU}$ : perceived usefulness.

${ }^{\mathrm{c}} \mathrm{AI}$ : adoption intention.

${ }^{\mathrm{d}}$ SI: social influence.

${ }^{\mathrm{e}} \mathrm{PD}$ : perceived drawbacks.

${ }^{f} \mathrm{~PB}$ : perceived benefits.

${ }^{\mathrm{g}} \mathrm{SE}$ : self-efficacy.

Figure 2. Structural model results; standardized path coefficients $(\beta)$ are shown. $* * * P<.001 ; * * P<.01$; ns: not significant $(P>.05)$.

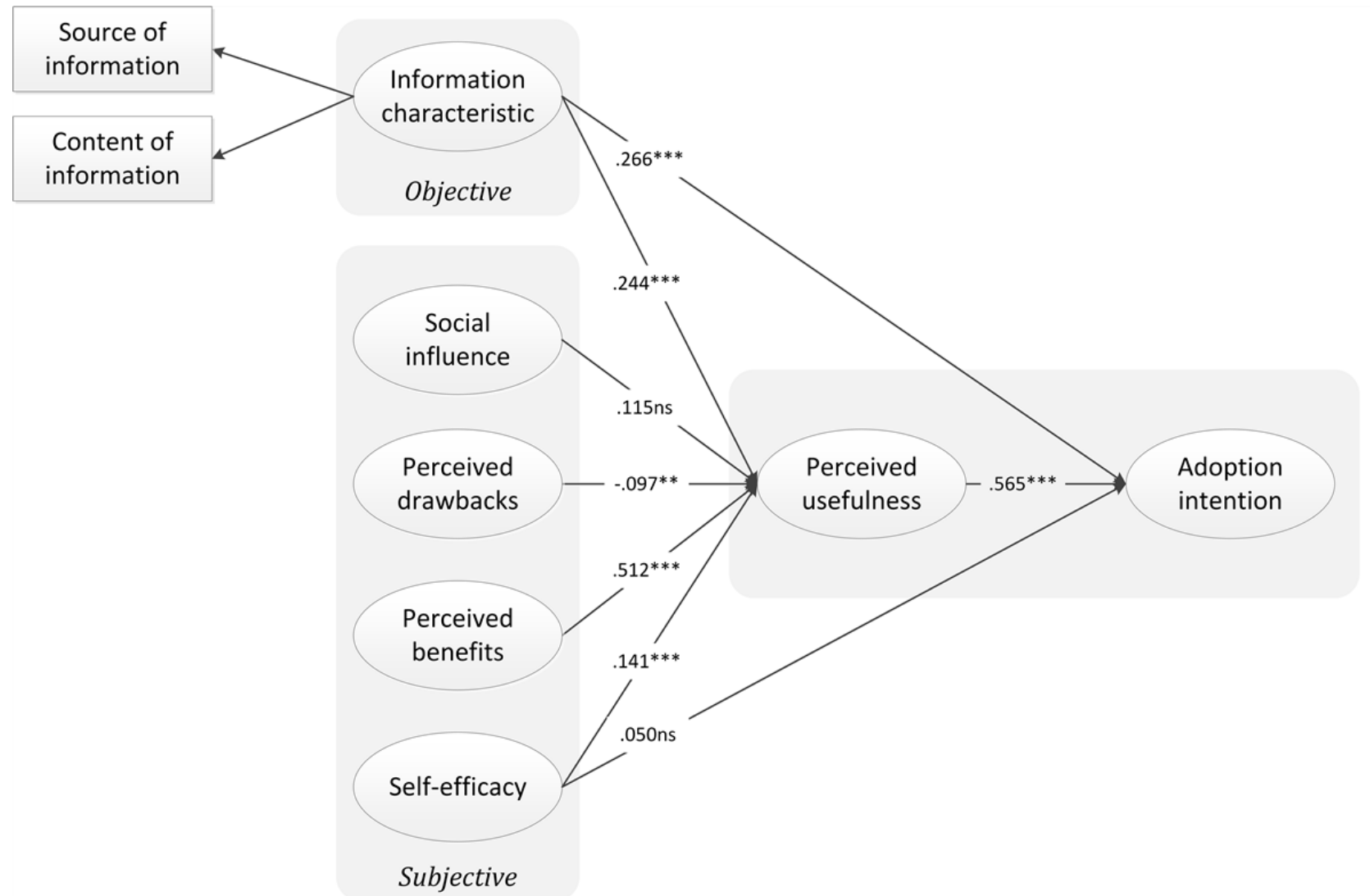




\section{Analysis of Mediating Effects}

To test the indirect effects, bias-corrected bootstrapping with 5000 iterations was implemented to obtain the structural model path significance levels for indirect effects [58]. Bootstrapping, a nonparametric approach, was superior to other approaches in testing mediation models because it does not assume multivariate normality $[59,60]$. Table 7 shows that perceived usefulness fully mediated the effect of perceived drawbacks, perceived benefits, and self-efficacy on adoption intention, whereas perceived usefulness partially mediated the effect of information characteristics on adoption intention.

Table 7. Mediation effect analysis.

\begin{tabular}{lllllll}
\hline $\begin{array}{l}\text { Constructs of measure- } \\
\text { ment }\end{array}$ & $\begin{array}{l}\text { Standardized indirect } \\
\text { effect }\end{array}$ & Bias-corrected values & & Percentile & Mediating effect \\
\hline $\mathrm{IC}^{\mathrm{a}} \rightarrow \mathrm{PU}^{\mathrm{b}} \rightarrow \mathrm{AI}^{\mathrm{c}}$ & 0.138 & $95 \% \mathrm{CI}$ & $P$ value & $95 \%$ CI & $P$ value \\
$\mathrm{SI}^{\mathrm{d}} \rightarrow \mathrm{PU} \rightarrow \mathrm{AI}$ & 0.065 & 0.069 to 0.218 & $<.001$ & 0.071 to 0.220 & $<.001$ & Partial \\
$\mathrm{PD}^{\mathrm{e}} \rightarrow \mathrm{PU} \rightarrow \mathrm{AI}$ & -0.055 & -0.014 to 0.150 & .10 & -0.020 to 0.145 & .13 & No \\
$\mathrm{PB}^{\mathrm{f}} \rightarrow \mathrm{PU} \rightarrow \mathrm{AI}$ & 0.289 & -0.094 to -0.023 & .002 & -0.091 to -0.020 & .004 & Fully \\
$\mathrm{SE}^{\mathrm{g}} \rightarrow \mathrm{PU} \rightarrow \mathrm{AI}$ & 0.079 & 0.183 to 0.426 & $<.001$ & 0.178 to 0.419 & $<.001$ & Fully \\
\hline
\end{tabular}

${ }^{\mathrm{a}} \mathrm{IC}$ : information characteristics.

${ }^{\mathrm{b}} \mathrm{PU}$ : perceived usefulness.

${ }^{\mathrm{c}} \mathrm{AI}$ : adoption intention.

${ }^{\mathrm{d}} \mathrm{SI}$ : social influence.

e PD: perceived drawbacks.

${ }^{\mathrm{f}} \mathrm{PB}$ : perceived benefits.

${ }^{\mathrm{g}} \mathrm{SE}$ : self-efficacy.

\section{Discussion}

\section{Principal Findings}

This study set out to determine the factors affecting people's intention of adopting health information on the internet, and the IAM-HBM model was applied. In general, this combined model provided an excellent fit to the data. Our research supports perceived drawbacks, perceived benefits, self-efficacy, perceived usefulness, and information characteristics as factors associated with the intention to adopt online prevention and treatment information to prevent an epidemic in the context of COVID-19.

\section{Evidence-Based Information Plays an Important Role}

In the study, information characteristics can strengthen perceived usefulness to adopt health information. In addition, the quality and the source of information influence the perceived usefulness and indirectly impact adoption intention. People are inclined to take in evidence-based information rather than misinformation on the internet [61,62]. Therefore, health communication should include more evidence-based information and should meet the public's health demand [7]. Swamped by information on the internet, if the information is expressed more reliably or if its publisher is more professional and authoritative, the public will have a more robust perception of the usefulness of the information, thus increasing individuals' willingness to adopt the information. At the same time, in the face of information overload, especially where some information constituted rumors, the public, who lack professional knowledge, will balance the outcomes of adoption information behavior. Many online repositories full of valuable content are underutilized, becoming

"information junkyards" [63], and during the COVID-19 pandemic, an infodemic could be triggered by rumors. As information flow has improved, infodemic prevention and management using facts and evidence can mitigate the next infodemic $[64,65]$.

\section{Improving the Capacity to Obtain Public Information to Fight Mixed Messages}

The public's perceived drawbacks, perceived benefits, and self-efficacy had significant influences on perceived usefulness. Members of the public conduct a cost-benefit analysis before adopting healthy behaviors, in which they weigh the effectiveness of the adoption against the possible cost and risk of time-consuming impediments. As a result, the more benefits and fewer drawbacks one perceives, the more that the health benefits of the adoption behavior outweigh the health risks, resulting in higher perceived usefulness by individuals in considering online health information to prevent COVID-19.

However, only by improving the public's media literacy and their ability to perceive information can they correctly recognize the obstacles and benefits. At the same time, greater health literacy can improve public health self-efficacy, resulting in increased confidence in adopting healthy behaviors or changing bad behaviors. Many people have limited health literacy [66]; health communication and education are the most cost-effective means to improve health literacy [67]. Therefore, in the release of COVID-19-related health information, attention should be paid to improving public information capacity. For example, officials could actively hold health lectures and disclose health 
information, and relevant experts could improve the public's capacity regarding obtaining information.

Simultaneously, with the continuous enrichment of social media, it is difficult for social communication based on social media to achieve full, comprehensive, and balanced transmission of information. We need to avoid falling into information cocoons and confirmation bias [68], and we need to measure the quality of information from an overall perspective.

\section{Government Has Greater Influence Than Family and Friends}

Surprisingly, our analysis did not support the hypothesis that social influence is positively associated with perceived usefulness of COVID-19 prevention and treatment information. This finding was counterintuitive, and previous research showed that social networks positively affect people by encouraging them to adopt different health behavior intentions [69].

We think that government press conferences and news-based public opinion during the COVID-19 pandemic in China have weakened social influence on people's perception and acceptance of health information for the following reasons. First, since the SARS epidemic in 2003, the Chinese government has reformed the news release concept and system. In response to the emergencies, the Chinese government issued a series of policy documents and established the State Council Information Office's three-level news spokesman system for all central ministries and provincial-level people's governments [70]. Second, governments at all levels use various channels to publicize, in a timely manner, the prevention and treatment information regarding COVID-19, the latest situation regarding the pandemic, and other public concerns, providing the public with a low threshold and low-cost direct information feedback channel [71]. The government also invited medical experts, such as Dr Zhong Nanshan, Head of the National Team for Control of Novel Coronavirus, to communicate with the public, and this strategy gained public trust [72]. Finally, China's political system practices high-quality and high-efficiency unified decision making, and they have strict controls over content such as social media [73]. For example, Facebook, Twitter, and YouTube are not allowed in mainland China [74], and information monitoring and timely rumor controls are also available within popular social media platforms, such as WeChat and Sina Weibo [75]. Therefore, the government exerted its full influence during the pandemic to position itself as the primary influence [76].
However, social media is both a source of the infodemic and a public health tool [77]. Therefore, it is necessary to include social media platforms in public information dissemination; rethinking the role of public communication will also be necessary to assume corresponding responsibility during the pandemic. The responsibility is not only to delete information but, as much as possible, to ensure the diversity of the information environment to a sufficient degree; this will enable high-quality public content and thereby increase public participation [64].

\section{Conclusions}

In a public health emergency, the online infodemic forces the public to negotiate with prevention and treatment information. By integrating IAM and HBM, this study provided the insight and understanding that perceived usefulness and adoption intention of online health information could be influenced by information characteristics, people's perceptions of drawbacks and benefits, and self-efficacy. Moreover, people also exhibit proactive behavior rather than reactive behavior. Thus, we should consider these factors to help the informed public obtain useful information via two approaches: one is to control the quality of information and the other is to improve the public's capacity to obtain information, in order to promote trusted information and to fight misinformation. This will, in turn, contribute to saving lives as the pandemic continues to unfold and run its course.

\section{Limitations}

We administered the questionnaire survey during the stage of the pandemic in mainland China when it was under control, which was when the outbreak in China had passed the initial panic stage. People at different stages of the pandemic may have been influenced differently by the influencing factors. Therefore, although we found that social influence had no significant effect on perceived usefulness of information, a more comprehensive future study is suggested to explore whether this is due to social context, stage of the pandemic, or other factors. Moreover, this cross-sectional study was conducted using the WJX web application, and sample populations had a certain amount of experience in filling out online questionnaires and internet use. Therefore, a more comprehensive future study is suggested to include offline and online participants to expand the framework's application scope.

\section{Acknowledgments}

This study was funded by the National Natural Science Foundation of China (No. 71704118).

\section{Conflicts of Interest}

None declared.

\section{Multimedia Appendix 1}

Path diagram of the information adoption model (IAM)-health belief model (HBM).

[PNG File, 444 KB-Multimedia Appendix 1] 


\section{References}

1. There are more than 2.36 million cases of COVID-19 globally. People's Daily. URL: https://news.sina.cn/gj/2020-04-20/ detail-iirczymi7386584.d.html?vt=4\&wm=3164 0008jishu [accessed 2020-04-20]

2. Munich Security Conference. World Health Organization. 2020 Feb 15. URL: https://www.who.int/director-general/speeches/ detail/munich-security-conference [accessed 2020-02-15]

3. Tangcharoensathien V, Calleja N, Nguyen T, Purnat T, D'Agostino M, Garcia-Saiso S, et al. Framework for managing the COVID-19 infodemic: Methods and results of an online, crowdsourced WHO technical consultation. J Med Internet Res 2020 Jun 26;22(6):e19659 [FREE Full text] [doi: 10.2196/19659] [Medline: 32558655]

4. Dumbrell D, Steele R. Putting the public into public health information dissemination: Social mediahealth-related web pages. In: Proceedings of the Seventeenth Australasian Document Computing Symposium. 2012 Dec Presented at: Seventeenth Australasian Document Computing Symposium; December 5-6, 2012; Dunedin New Zealand p. 135-138. [doi: 10.1145/2407085.2407104]

5. Risk A, Dzenowagis J. Review of internet health information quality initiatives. J Med Internet Res 2001;3(4):e28 [FREE Full text] [doi: 10.2196/jmir.3.4.e28] [Medline: 11772543]

6. Mheidly N, Fares J. Leveraging media and health communication strategies to overcome the COVID-19 infodemic. J Public Health Policy 2020 Dec;41(4):410-420 [FREE Full text] [doi: 10.1057/s41271-020-00247-w] [Medline: 32826935]

7. Zarocostas J. How to fight an infodemic. Lancet 2020 Feb;395(10225):676. [doi: 10.1016/s0140-6736(20)30461-x]

8. Hou Z, Du F, Zhou X, Jiang H, Martin S, Larson H, et al. Cross-country comparison of public awareness, rumors, and behavioral responses to the COVID-19 epidemic: Infodemiology study. J Med Internet Res 2020 Aug 03;22(8):e21143 [FREE Full text] [doi: 10.2196/21143] [Medline: 32701460]

9. Larson HJ. A call to arms: Helping family, friends and communities navigate the COVID-19 infodemic. Nat Rev Immunol 2020 Aug;20(8):449-450 [FREE Full text] [doi: 10.1038/s41577-020-0380-8] [Medline: 32616908]

10. Ashrafi-Rizi H, Kazempour Z. Information diet in Covid-19 crisis: A commentary. Arch Acad Emerg Med 2020;8(1):e30 [FREE Full text] [Medline: $\underline{\text { 32232215] }}$

11. Berg S. The well-informed patient: A new breed of health care consumer. Asthma Mag 2005 Jul;10(4):28-30. [doi: 10.1016/j.asthmamag.2005.06.005]

12. Yeh NC. Citizens' health information behaviors during SARS spread periods in Taiwan. J Libr Inf Stud 2003;1:95-110 [FREE Full text]

13. Teng Y, Bi D, Xie G, Jin Y, Huang Y, Lin B, et al. Dynamic forecasting of Zika epidemics using Google Trends. PLoS One 2017;12(1):e0165085 [FREE Full text] [doi: 10.1371/journal.pone.0165085] [Medline: 28060809]

14. Bora K, Das D, Barman B, Borah P. Are internet videos useful sources of information during global public health emergencies? A case study of YouTube videos during the 2015-16 Zika virus pandemic. Pathog Glob Health 2018 Sep;112(6):320-328 [FREE Full text] [doi: 10.1080/20477724.2018.1507784] [Medline: 30156974]

15. Hua J, Shaw R. Corona virus (COVID-19) "infodemic" and emerging issues through a data lens: The case of China. Int J Environ Res Public Health 2020 Mar 30;17(7):2309 [FREE Full text] [doi: 10.3390/ijerph17072309] [Medline: 32235433]

16. Li HO, Bailey A, Huynh D, Chan J. YouTube as a source of information on COVID-19: A pandemic of misinformation? BMJ Glob Health 2020 May;5(5):E002604 [FREE Full text] [doi: 10.1136/bmjgh-2020-002604] [Medline: 32409327]

17. Boyer C, Frossard C, Gaudinat A, Hanbury A, Falquetd G. How to sort trustworthy health online information? Improvements of the automated detection of HONcode criteria. Procedia Comput Sci 2017 Apr;121(4):940-949. [doi:

10.1016/j.procs.2017.11.122]

18. Houston TK, Sands DZ, Nash BR, Ford DE. Experiences of physicians who frequently use e-mail with patients. Health Commun 2003 Oct;15(4):515-525. [doi: 10.1207/s15327027hc1504 08]

19. Cailin O, James O. Why do we tend to believe rumors? Tencent. 2020 Feb 22. URL: https://new.qq.com/omn/20200222/ 20200222A0OKXT00.html [accessed 2020-02-23]

20. Rosenstock I, Strecher V, Becker M. The health belief model and HIV risk behavior change. In: DiClemente RJ, Peterson JL, editors. Preventing AIDS: Theories and Methods of Behavioral Interventions. Boston, MA: Springer; 1994:5-24.

21. Sussman SW, Siegal WS. Informational influence in organizations: An integrated approach to knowledge adoption. Inf Syst Res 2003 Mar;14(1):47-65. [doi: 10.1287/isre.14.1.47.14767]

22. Davis FD, Bagozzi RP, Warshaw PR. User acceptance of computer technology: A comparison of two theoretical models. Manage Sci 1989 Aug;35(8):982-1003. [doi: 10.1287/mnsc.35.8.982]

23. Watts S, Zhang W. Capitalizing on content: Information adoption in two online communities. J Assoc Inf Syst 2008 Feb;9(2):73-94. [doi: 10.17705/1jais.00149]

24. Ha S, Ahn J. Why are you sharing others' tweets?: The impact of argument quality and source credibility on information sharing behavior. In: Proceedings of the 32nd International Conference on Information Systems. 2011 Presented at: 32nd International Conference on Information Systems; December 4-7, 2011; Shanghai, China p. 1195 URL: https://aisel. aisnet.org/cgi/viewcontent.cgi?article $=1271 \&$ context=icis 2011

25. Rosenstock IM. The health belief model and preventive health behavior. Health Educ Monogr 1974 Dec 01;2(4):354-386. [doi: 10.1177/109019817400200405] 
26. Champion V, Skinner C. The health belief model. In: Glanz K, Rimer BK, Viswanath KV, editors. Health Behavior and Health Education: Theory, Research and Practice. 4th edition. San Francisco, CA: Jossey-Bass; 2008:46-65.

27. Harrison J, Mullen P, Green L. A meta-analysis of studies of the health belief model with adults. Health Educ Res 1992 Mar;7(1):107-116. [doi: 10.1093/her/7.1.107] [Medline: 10148735]

28. Dong Z. How to persuade adolescents to use nutrition labels: Effects of health consciousness, argument quality, and source credibility. Asian J Commun 2015 Feb 19;25(1):84-101. [doi: 10.1080/01292986.2014.989241]

29. Mou J, Shin D, Cohen J. Health beliefs and the valence framework in health information seeking behaviors. Inf Technol People 2016 Nov 07;29(4):876-900. [doi: 10.1108/itp-06-2015-0140]

30. Cheung CM, Lee MK, Rabjohn N. The impact of electronic word - of - mouth. Internet Res 2008 Jun 06;18(3):229-247. [doi: $10.1108 / 10662240810883290$ ]

31. Erkan I, Evans C. The influence of eWOM in social media on consumers' purchase intentions: An extended approach to information adoption. Comput Human Behav 2016 Aug;61:47-55. [doi: 10.1016/j.chb.2016.03.003]

32. Ahadzadeh AS, Pahlevan Sharif S, Ong FS, Khong KW. Integrating health belief model and technology acceptance model: An investigation of health-related internet use. J Med Internet Res 2015 Feb 19;17(2):e45 [FREE Full text] [doi: 10.2196/jmir.3564] [Medline: 25700481]

33. Jeihooni AK, Rakhshani T. The effect of educational intervention based on health belief model and social support on promoting skin cancer preventive behaviors in a sample of Iranian farmers. J Cancer Educ 2019 Apr;34(2):392-401. [doi: 10.1007/s13187-017-1317-1] [Medline: 29313300]

34. Venkatesh V, Morris MG, Davis GB, Davis FD. User acceptance of information technology: Toward a unified view. MIS Q 2003 Jan 11;27(3):425-106. [doi: 10.2307/30036540]

35. Portz JD, Bayliss EA, Bull S, Boxer RS, Bekelman DB, Gleason K, et al. Using the technology acceptance model to explore user experience, intent to use, and use behavior of a patient portal among older adults with multiple chronic conditions: Descriptive qualitative study. J Med Internet Res 2019 Apr 08;21(4):e11604 [FREE Full text] [doi: 10.2196/11604] [Medline: $\underline{30958272]}$

36. Redelmeier DA, Kraus NC. Patterns in patient access and utilization of online medical records: Analysis of MyChart. J Med Internet Res 2018 Feb 06;20(2):e43 [FREE Full text] [doi: 10.2196/jmir.8372] [Medline: 29410386]

37. Zeithaml VA. Consumer perceptions of price, quality, and value: A means-end model and synthesis of evidence. J Mark 2018 Nov 19;52(3):2-22. [doi: 10.1177/002224298805200302]

38. Kim H, Chan H, Gupta S. Value-based adoption of mobile internet: An empirical investigation. Decis Support Syst 2007 Feb;43(1):111-126. [doi: 10.1016/j.dss.2005.05.009]

39. Carpenter CJ. A meta-analysis of the effectiveness of health belief model variables in predicting behavior. Health Commun 2010 Dec;25(8):661-669. [doi: 10.1080/10410236.2010.521906] [Medline: 21153982]

40. Yun EK. Development and Testing of a Model of Consumers' Health Information Seeking Behavior on the Internet [doctoral thesis]. Seoul, South Korea: Seoul National University; 2008.

41. Qin Z, Huo C. Research on the continuous intention of health information seeking via social media: Bade on the view of revenue-expenditure. J Mod Inf 2020 May;40(05):66-77. [doi: 10.3969/j.issn.1008-0821.2020.05.009]

42. Rosenstock IM. Historical origins of the health belief model. Health Educ Monogr 1974 Dec 01;2(4):328-335. [doi: $\underline{10.1177 / 109019817400200403]}$

43. Aronson E, editor. The Social Animal. 8th edition. New York, NY: Worth Publishers; 1995.

44. Li C. Persuasive messages on information system acceptance: A theoretical extension of elaboration likelihood model and social influence theory. Comput Human Behav 2013 Jan;29(1):264-275. [doi: 10.1016/j.chb.2012.09.003]

45. Johnson J, Meischke H. A comprehensive model of cancer-related information seeking applied to magazines. Hum Commun Res 1993 Mar;19(3):343-367. [doi: 10.1111/j.1468-2958.1993.tb00305.x]

46. McKinney V, Yoon K, Zahedi F. The measurement of web-customer satisfaction: An expectation and disconfirmation approach. Inf Syst Res 2002 Sep;13(3):296-315. [doi: 10.1287/isre.13.3.296.76]

47. Venkatesh V, Thong JYL, Xu X. Consumer acceptance and use of information technology: Extending the unified theory of acceptance and use of technology. MIS Q 2012;36(1):157. [doi: 10.2307/41410412]

48. Jacoby J, Kaplan L. The components of perceived risk: Advances in consumer research. In: Proceedings of the Third Annual Conference of the Association for Consumer Research. 1972 Presented at: Third Annual Conference of the Association for Consumer Research; November 3-5, 1972; Chicago, IL p. 382-393.

49. Peter JP, Tarpey Sr LX. A comparative analysis of three consumer decision strategies. J Consum Res 1975 Jun;2(1):29-37. [doi: 10.1086/208613]

50. Yoo W, Choi D. Predictors of expressing and receiving information on social networking sites during MERS-CoV outbreak in South Korea. J Risk Res 2019 Feb 11;23(7-8):912-927. [doi: 10.1080/13669877.2019.1569105]

51. Johnson JD, Donohue WA, Atkin CK, Johnson S. A comprehensive model of information seeking. Sci Commun 2016 Aug 18;16(3):274-303. [doi: 10.1177/1075547095016003003]

52. Tsai H, Bagozzi RP. Contribution behavior in virtual communities: Cogntive, emotional, and social influences. MIS Q 2014 Jan 1;38(1):143-163. [doi: 10.25300/misq/2014/38.1.07] 
53. Hair J, Black W, Babin B, Anderson R. Multivariate Data Analysis: A Global Perspective. 7th edition. Upper Saddle River, NJ: Prentice Hall; 2010.

54. Nunnally JC, Bernstein IH. Psychometric Theory. 3rd edition. New York, NY: McGraw-Hill; 1994.

55. Fornell C, Larcker DF. Evaluating structural equation models with unobservable variables and measurement error. J Mark Res 2018 Nov 28;18(1):39-50. [doi: 10.1177/002224378101800104]

56. Anderson JC, Gerbing DW. Structural equation modeling in practice: A review and recommended two-step approach. Psychol Bull 1988 May;103(3):411-423. [doi: 10.1037/0033-2909.103.3.411]

57. Bagozzi RP, Phillips LW. Representing and testing organizational theories: A holistic construal. Adm Sci Q 1982 Sep;27(3):459-489. [doi: 10.2307/2392322]

58. Preacher KJ, Hayes AF. Asymptotic and resampling strategies for assessing and comparing indirect effects in multiple mediator models. Behav Res Methods 2008 Aug;40(3):879-891. [doi: 10.3758/BRM.40.3.879]

59. Bollen KA, Stine R. Direct and indirect effects: Classical and bootstrap estimates of variability. Sociol Methodol 1990;20:115-140. [doi: 10.2307/271084]

60. Mackinnon DP, Lockwood CM, Williams J. Confidence limits for the indirect effect: Distribution of the product and resampling methods. Multivariate Behav Res 2004 Jan 01;39(1):99 [FREE Full text] [doi: 10.1207/s15327906mbr3901 4] [Medline: 20157642]

61. Pulido CM, Villarejo-Carballido B, Redondo-Sama G, Gómez A. COVID-19 infodemic: More retweets for science-based information on coronavirus than for false information. Int Sociol 2020 Apr 15;35(4):377-392. [doi: $10.1177 / 0268580920914755]$

62. Eysenbach G, Powell J, Kuss O, Sa E. Empirical studies assessing the quality of health information for consumers on the world wide web: A systematic review. JAMA 2002;287(20):2691-2700. [doi: 10.1001/jama.287.20.2691] [Medline: 12020305]

63. McDermott R. Why information technology inspired but cannot deliver knowledge management. Calif Manage Rev 1999 Jul;41(4):103-117. [doi: 10.2307/41166012]

64. Eysenbach G. How to fight an infodemic: The four pillars of infodemic management. J Med Internet Res 2020 Jun 29;22(6):e21820 [FREE Full text] [doi: 10.2196/21820] [Medline: 32589589]

65. Guterres A. Tweet. Twitter. 2020 Apr 14. URL: https://twitter.com/antonioguterres/status/1250095790959267841?s=20 [accessed 2020-04-14]

66. Berkman ND, Sheridan SL, Donahue KE, Halpern DJ, Crotty K. Low health literacy and health outcomes: An updated systematic review. Ann Intern Med 2011 Jul 19;155(2):97-107. [doi: 10.7326/0003-4819-155-2-201107190-00005] [Medline: 21768583]

67. Institute of Medicine. Health Literacy: A Prescription to End Confusion. Washington, DC: The National Academies Press; 2004.

68. Sunstein CR. Infotopia: How Many Minds Produce Knowledge. New York, NY: Oxford University Press; 2006.

69. Ryu I, Choi H. The effect of social influence on flow, perceived usefulness and intention to use in online community. J Inf Syst 2008 Jun 30;17(2):113-135. [doi: 10.5859/kais.2008.17.2.113]

70. Tian L, Yang Y. The quality assessment study of local government press conferences is based on case studies of COVID-19 press conferences in H province. Newsmaker 2020;5:8-13 [FREE Full text] [doi: 10.16017/j.cnki.xwahz.2020.05.003]

71. Zhong Nanshan's 12 latest judgments on the epidemic are very impressive. People's Daily. 2020 Apr 12. URL: https:/ /baijiahao.baidu.com/s?id=1663732306125815219\&wfr=spider\&for=pc [accessed 2021-03-05]

72. Tencent News. Zhong Nanshan contributed to the coVID-19 outbreak?. URL: https://xw.qq.com/partner/standard/ 20201015A0DFVC/20201015A0DFVC00?ADTAG=standard\&pgv ref=standard [accessed 2020-10-17]

73. Fang N. The country's fight against the epidemic highlights the strength of China's political system. People's Daily. 2020 Jul 10. URL: http://theory.people.com.cn/n1/2020/0710/c40531-31778127.html [accessed 2020-07-10]

74. Sonmez F. How Chinese officials 'like' banned Facebook. Phys.org. 2014 May 18. URL: https://phys.org/news/ 2014-05-chinese-facebook.html [accessed 2014-05-18]

75. Here are the tools to check and verify rumors about the epidemic. Cyberspace Administration of China. 2020 Feb 18. URL: http://www.cac.gov.cn/2020-02/18/c 1583567100466237.htm [accessed 2020-02-18]

76. Public opinion leadership of new media from the perspective of COVID-19 epidemic prevention and control publicity. CN-Healthcare. 2020 Jul 28. URL: https://www.cn-healthcare.com/articlewm/20200727/content-1133260.html [accessed 2020-07-28]

77. Ahmed ST. Managing news overload (MNO): The COVID-19 infodemic. Information 2020 Jul 25;11(8):375. [doi: 10.3390/info11080375]

\section{Abbreviations}

AVE: average variance extracted

CFA: confirmatory factor analysis

CFI: comparative fit index 
CR: composite reliability

ELM: elaboration likelihood model

GFI: goodness-of-fit index

HBM: health belief model

IACM: information acceptance model

IAM: information adoption model

IP: Internet Protocol

QR: Quick Response

RMSEA: root mean square error of approximation

SEM: structural equation modeling

TAM: technology acceptance model

TLI: Tucker-Lewis index

WHO: World Health Organization

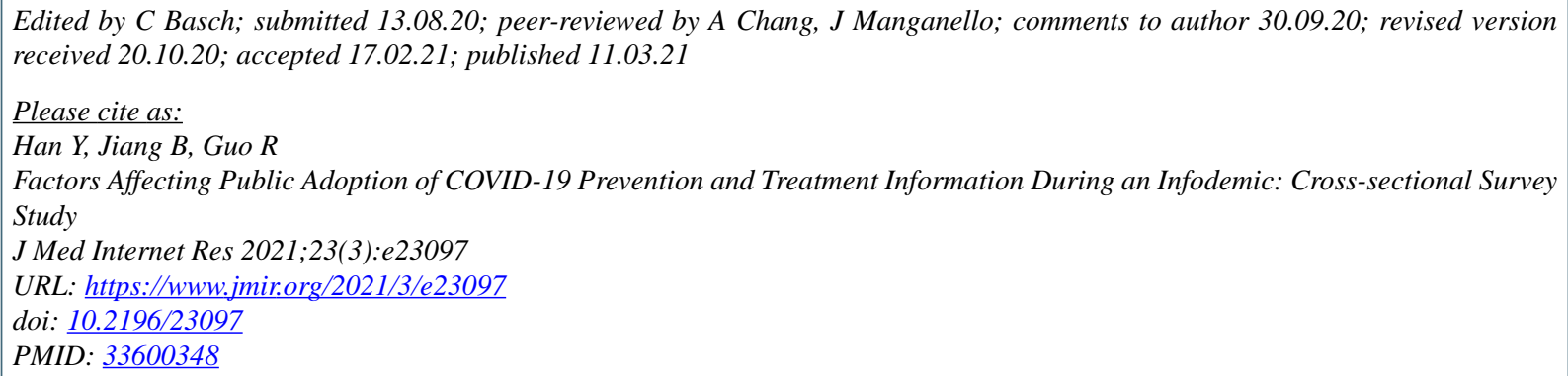

(C) Yangyang Han, Binshan Jiang, Rui Guo. Originally published in the Journal of Medical Internet Research (http://www.jmir.org), 11.03.2021. This is an open-access article distributed under the terms of the Creative Commons Attribution License (https://creativecommons.org/licenses/by/4.0/), which permits unrestricted use, distribution, and reproduction in any medium, provided the original work, first published in the Journal of Medical Internet Research, is properly cited. The complete bibliographic information, a link to the original publication on http://www.jmir.org/, as well as this copyright and license information must be included. 